\title{
Factors controlling geochemistry of garnet in calcic skarn rocks: A case study from the Cuihongshan Fe-W- Mo skarn deposit, NE China
}

\author{
XIANGHUI FEI ${ }^{1}$, ZHAOCHONG ZHANG ${ }^{1}$, , ZHIGUO
}

CHENG $^{1}$, AND M. SANTOSH ${ }^{1,2}$

${ }^{1}$ State Key Laboratory of Geological Processes and Mineral

Resources, China University of Geosciences, Beijing 100083, China (Correspondence: zczhang@,cugb.edu.cn)

${ }^{2}$ Department of Earth Sciences, University of Adelaide, South Australia 5005, Australia

Grossular (Grs)-andradite (Adr) solid solutions of garnet are common in hydrothermal skarn deposits, and provide important insights into deposit types, hydrothermal processes, and physicochemical conditions of ore formation. Here we investigate garnet occurring in association with calcic skarn rocks in the Cuihongshan Fe-W-Mo skarn deposit located in NE China. The calcic skarn rocks contain three types of garnets. (1) Prograde type I Al-rich garnets display a compositional range of $\mathrm{Grs}_{18-80} \mathrm{Adr}_{10-75}$. This type of garnet shows markedly low rare earth element (REE) contents and is strongly depleted in light rare earth elements (LREE) relative to heavy rare earth elements (HREE). (2) Fe-rich retrograde type II garnets own wide compositional variations $\left(\mathrm{Grs}_{1-}\right.$ ${ }_{47} \mathrm{Adr}_{30-95}$ ) with flat REE patterns. (3) Fe-rich retrograde type III garnets exhibit relatively narrow compositional variations of $\mathrm{Grs}_{0.1-12} \mathrm{Adr}_{85-97}$ with LREE-enrichment, flat HREE patterns. All garnets contain considerable $\mathrm{Sn}$ and $\mathrm{W}$ contents. Type II garnet containing intermediate Grs-Adr compositions shows the highest Sn contents, albeit the lowest $\mathrm{W}$ range.

Based on microscopic obersavation and analytical results, the zoning is likely driven by external factors such as compositions of the hydrothermal fluid. The garnet grains in the Cuihongshan deposit favoured an Yttrogarnet (YAG) type substitution based on the low $\mathrm{Na}$ concentration and nonlinear relationship between $\mathrm{F}$ and REE. According to the Gibbs free energy change of Grs-Adr solid solution, REE concentrations in garnet are probably influenced by the relative Grs/Adr proportion and temperature of the system. This binary solid solution exhibits an asymmetric model. Moreover, the LREE-HREE fractionation character of garnet can be attributed to relative compositions of Grs-Adr system. The $\mathrm{W}$ and $\mathrm{Sn}$ contents in garnet grains display consistent behavior with scheelite and cassiterite precipitation respectively, which indicate that they can be used as indicators for the exploration of W-Sn skarn deposits. 